\title{
Study on the Compound Effects of Interceptor with Stern Flap for Two Fast Monohulls
}

\author{
J. F. Tsai, Professor NTU J. L. Hwang, Vice President USDDC \\ Department of Engineering Science and Ocean Engineering, National Taiwan University \\ No.1, Sec. 4, Roosevelt Road, Taipei, Taiwan, R.O.C. \\ United Ship Design and Development Center \\ 14F, 27 Sec. 2, Chung-cheng E. Road, Tamshui, Taipei, Taiwan R.O.C. \\ iftsai@ntu.edu.tw ilhwang@mail.usddc.org.tw
}

\begin{abstract}
The effect of trim mechanisms (including stern flap, interceptor and integrated interceptor with stern flap) on resistance reduction were examined in this study. Two planing crafts were used for the resistance test. The first one is a 20 -meter patrol boat and the test was conducted at the towing tank of National Taiwan University(NTU), Taiwan, ROC. The seond one is 29.5-meter patrol boat tested at HSVA towing tank, The Hamburg Ship Model Basin, Germany. The results show that a well-designed trim mechanism can reduce the running trim and the resistance of the planing craft. It also show that the trim mechanisms have a best resistance reduction effect at the volume Froude number between 2.0 and 2.5. The drag reduction of integrated interceptor with stern flap is better than that of interceptor alone and stern flap alone.
\end{abstract}

\section{INTRODUCTION}

The planning craft has a resistance hump located at the Froude number between 0.4 and 0.5 . A bare planing craft needs a positive running trim to lift the hull and to overcome the resistance hump. In general, the optimum running trim is about 4 degrees for a bare planing craft [1]. However, some research $[2,3,4]$ showed that trim mechanisms, such as stern wedge, stern flap and interceptor, could reduce the running trim and the drag at the design speed. Karafiath and Fisher [2] showed that the stern wedge could reduce 0.4 to 2.0 degrees of running trim and a $2 \%$ saving of the fuel consumption at design speed. In recent years, the stern flap has been retrofit on large combatant-sized U.S. Navy vessels $[5,6]$. The performance benefits of decreased ship power, leading directly to reduced fuel consumption, reduced emissions, and increased speed and range, have been proven from full-scale trials. Tsai and Huang $[7,8]$ showed that the interceptor could effectively reduce the running trim and decrease the resistance of a planing hull. Most recently, Cusanelli and Karatiath $[6,9]$ showed that the integrated wedge-flap could reduce the powering requirements compared to wedge only.

The trim mechanisms have proven themselves on the performance of drag reduction. The integrated wedge-flap configuration also has better performance than wedge only. In this study, the interceptor, stern flap and integrated interceptor-stern flap will be designed for two high speed planing crafts. The resistance tests will be conducted to examine the performance of the designed trim mechanisms.

\section{THE 2OM PATROL BOAT NTU MODEL}

The first planning patrol boat is $20 \mathrm{~m}$ in length and $4.1 \mathrm{~m}$ in breadth with a draft of $0.92 \mathrm{~m}$. The displacement is 32.1 tons and the designed speed is 40 knots. Fig. 1 shows the geometry of the patrol boat.

A FRP bare hull model, which is called NTU model thereafter, was manufactured with a scale ratio of $1 / 20$. The resistance tests were conducted at the towing tank of Department of Engineering Science and Ocean Engineering, National Taiwan University. The dimensions of the NTU towing tank are $130 \mathrm{~m} \times 8 \mathrm{~m} \times 4 \mathrm{~m}$, and the maximum speed of the towing carriage is $5 \mathrm{~m} / \mathrm{s}$. The experimental set up is shown in Fig.2. The measuring system includes a force gage, a trim gage and a potentiometer for heave motion at centre of gravity of the boat. The $95 \%$ confidence interval of the force gage is $0.014 \mathrm{Kg}$, the trim gage is 0.2 degrees, and the potentiometer is $0.2 \mathrm{~cm}$.

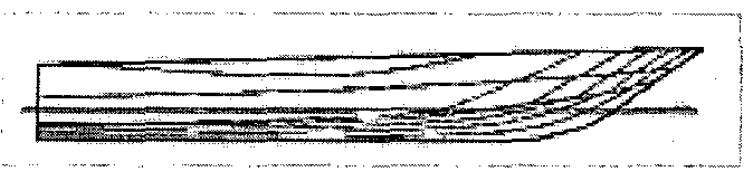

Fig.1. Geometry of the $20 \mathrm{~m}$ patrol boat tested at NTU

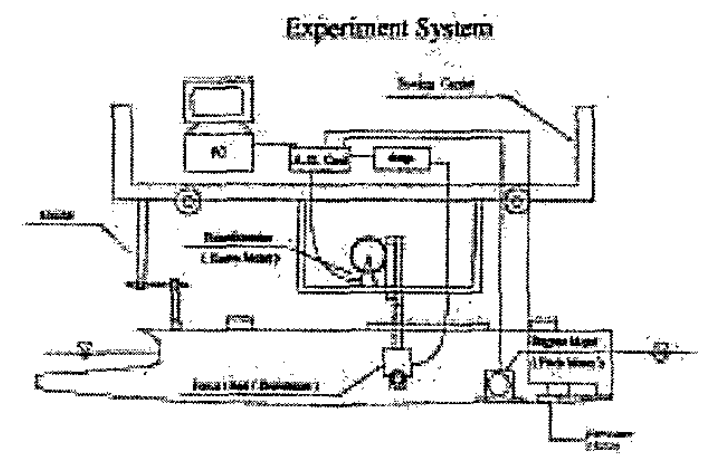

Fig.2. Resistance measuring system of NTU towing tank 
The resistance test results of the bare hull model are shown in Fig. 3. The figure shows the resistance coefficient $C_{t m_{1}}$ running trim and heave with volume Froude number Fn . The resistance coefficient $\mathrm{C}_{t m}$ and the volume Froude number are defined as:

$$
\begin{aligned}
& \mathrm{C}_{\mathrm{tm}} \frac{\mathrm{R}_{\mathrm{tm}}}{0.5 \mathrm{~V}^{2} \mathrm{~S}} \\
& \mathrm{~F}_{\mathrm{n}} \frac{\mathrm{V}}{\sqrt{\mathrm{g}^{1 / 3}}}
\end{aligned}
$$

Where $R_{\mathrm{tm}}$ is the total measured resistance of the model, $V$ is the speed of the craft model; $S$ is the wetted surface of the model and is the displacement volume.

In Fig. 3 , it is found that the resistance hump occurs at $F_{n}=1.1$ which is located at the maximum negative heave motion (The maximum loss of buoyancy). The running trim at design speed 40 knots $(F n=3.638)$ is 4 degrees. As $F n$ $>2.5$, the running trim decreases.

The height of interceptor was estimated by using boundary momentum thickness developed by Tsai and Huang[7]. The estimated height is about $1 \mathrm{~mm}$ for the NTU model. The resistance test with three interceptors of height $0.5 \mathrm{~mm}, 1.0 \mathrm{~mm}$ and $1.5 \mathrm{~mm}$ were conducted to seek the optimum interceptor height. Fig.4 shows the resistance/displacement coefficient of the NTU model with three different interceptors. Fig. 5 shows the drag reduction effect compared to the bare test result. The $1 \mathrm{~mm}$ interceptor has better drag reduction effect as $\mathrm{Fn}<=3.0$. The $18 \%$ maximum drag reduction occurred at $F n=2.4$. The drag reduction effect of $0.5 \mathrm{~mm}$ interceptor is better than that of $1.0 \mathrm{~mm}$ when volume Froude number is greater than 3.0 . There is $10 \%$ drag reduction at design speed. Fig. 6 shows the effect of interceptor on running trim. The over designed height of interceptor causes a trim by bow situation which increases the drag of the boat.

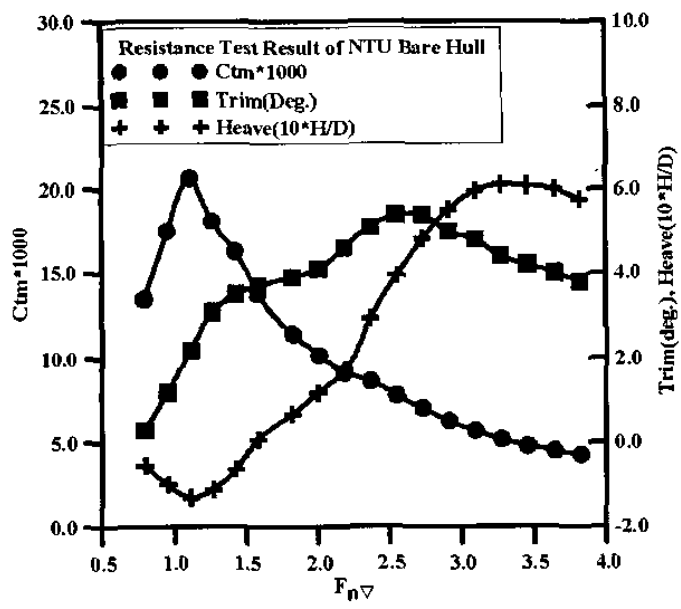

Fig.3. Resistance test results of Bare NTU model

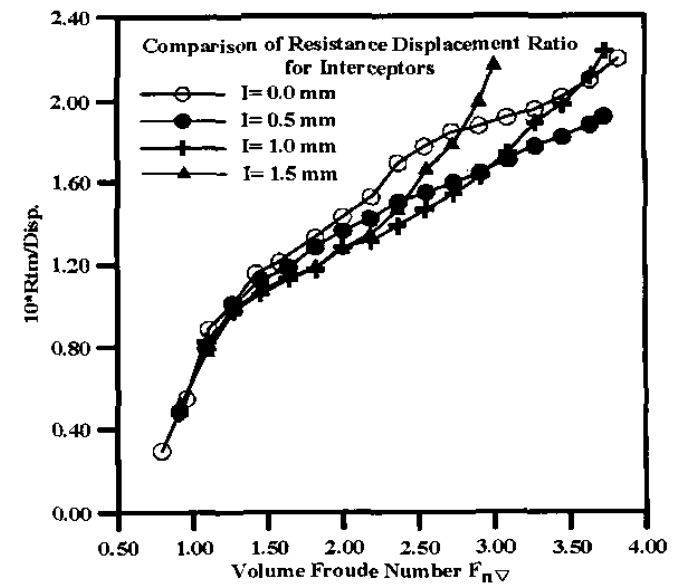

Fig.4. Resistance test results for three interceptors

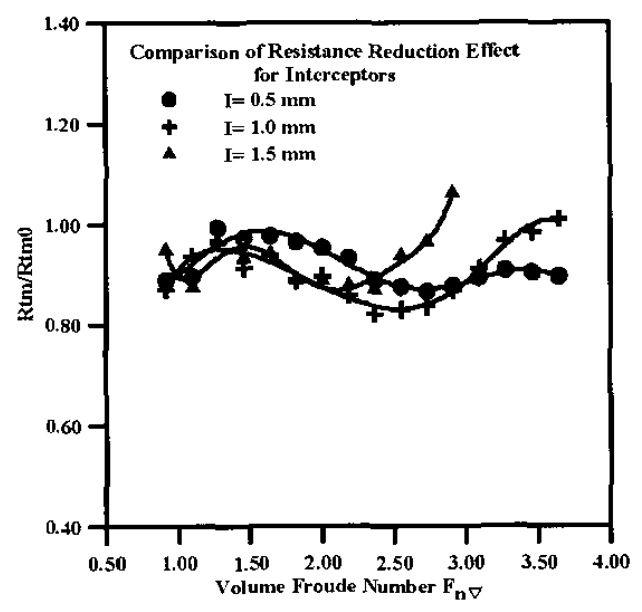

Fig.5. Drag reduction effect of interceptors

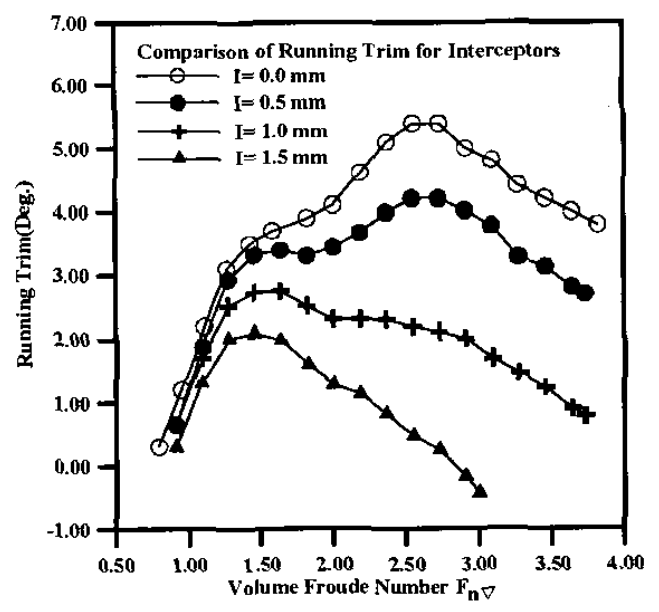

Fig.6. Running trims of interceptors 
Three stern flaps with different trailing edge down angles, including 4,8 , and 12 degrees, were installed on the transom of the NTU model to conduct resistance tests. The chord length of three stern flaps is $2.5 \%$ of ship length. The span is half the breadth of the transom plus the chord length of the stern flap. Fig.7 shows the effect of stern flaps on the resistance/displacement coefficient. Fig. 8 shows the drag reduction of the stern flaps. The results show that the 8 degree stern flap can reduce 1.2 degree running trim and have a $6 \%$ drag reduction at the design speed. The $20 \%$ maximum drag reduction also occurred at $\mathrm{Fn}=2.4$. Fig. 9 shows the test results of running trim for the three stern flaps.

Fig. 10 shows the schematic drawing of the combination of the integrated interceptor and stern flap. In order to find the optimum combination of the integrated interceptor and stern flap, the resistance tests of six combinations of the integrated interceptor of $0.5 \mathrm{~mm}$ and $1.0 \mathrm{~mm}$ with stern flap of 4,8 and 12 degrees were conducted. Fig.11 shows the drag reduction of the $0.5 \mathrm{~mm}$ interceptor integrated with the three stern flaps. Fig.12 shows the drag reduction of the 1.0 $\mathrm{mm}$ interceptor integrated with the three stern flaps.

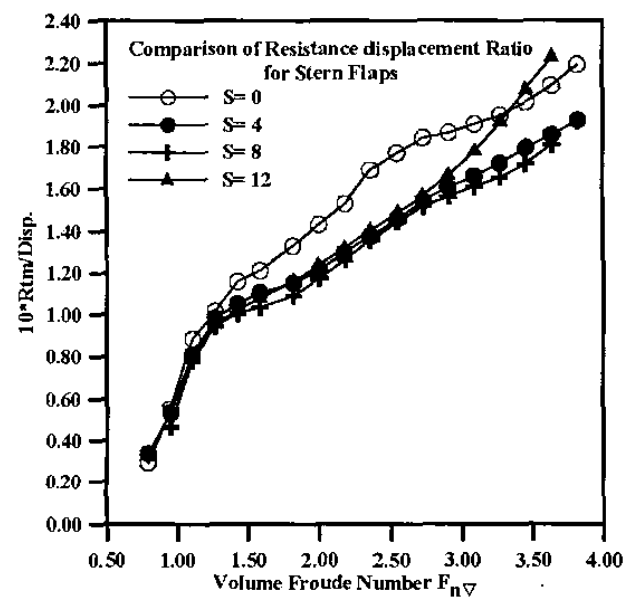

Fig.7. Resistance test results of stern flaps

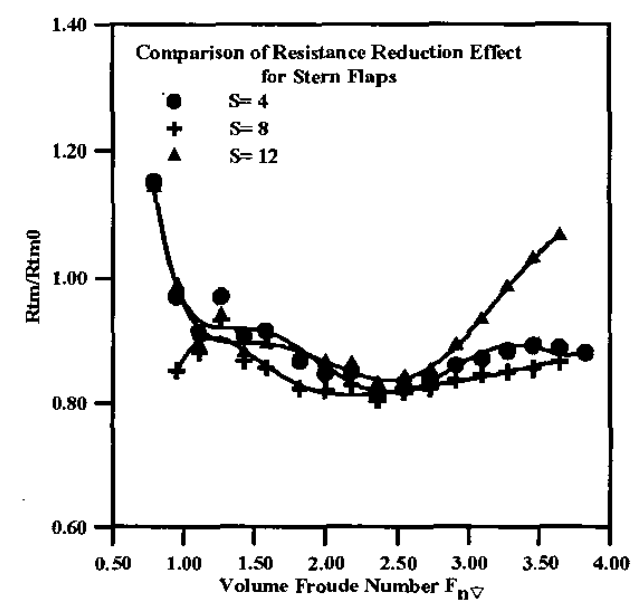

Fig. 8. Drag reduction effect of stern flaps
It is found that the drag reduction of the $0.5 \mathrm{~mm}$ interceptor integrated with 4-degree stern flap is the best one. It has $21 \%$ maximum drag reduction at $\mathrm{Fn}=2.55$ and $12 \%$ drag reduction at design speed 40 knots.

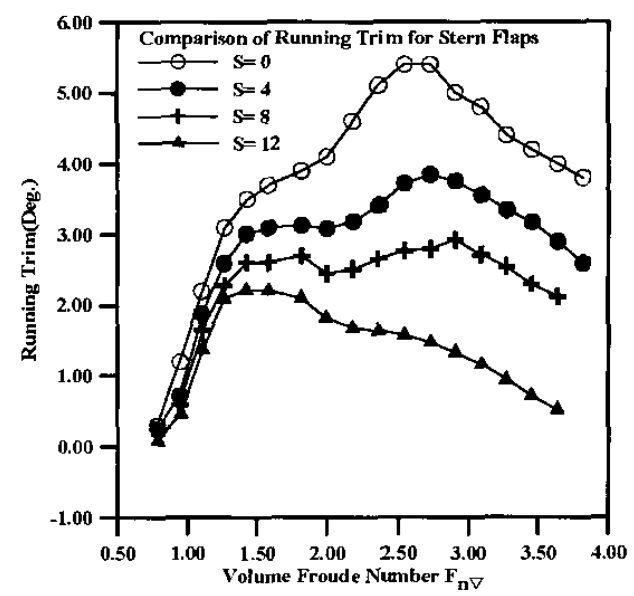

Fig.9. Running trims of stern flaps

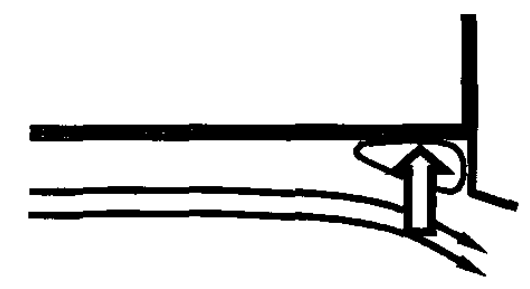

Fig.10. Schematic drawing of the integrated interceptor and stern flap.

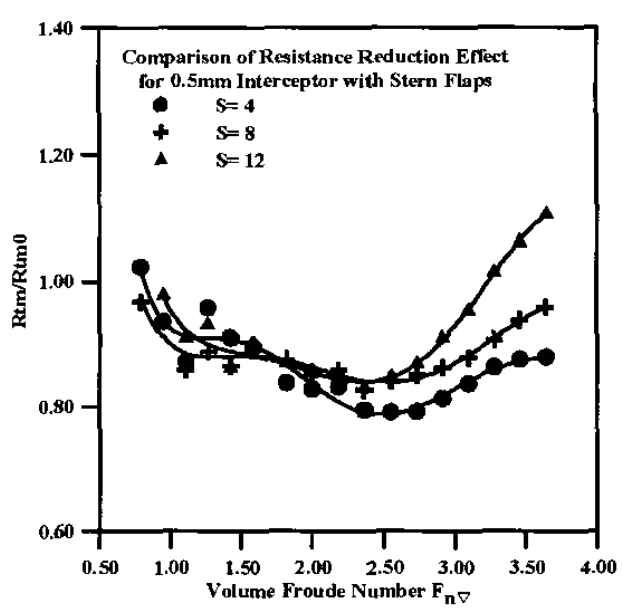

Fig.11. Drag reduction effect of the $0.5 \mathrm{~mm}$ interceptor integrated with three stern flaps. 


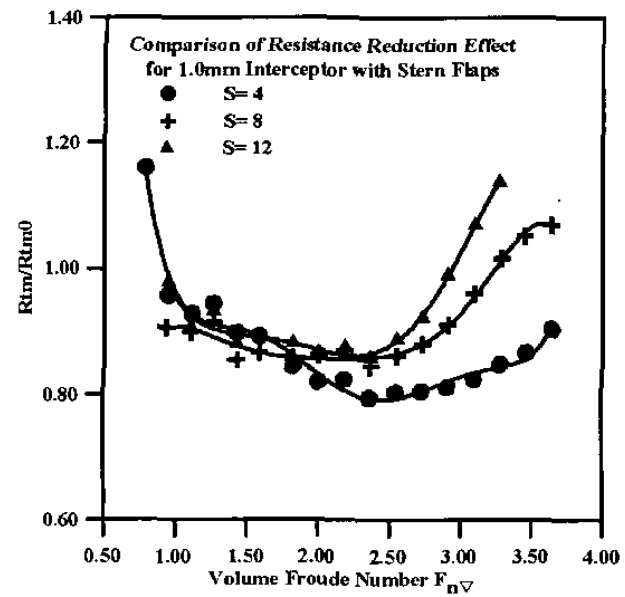

Fig.12. Drag reduction effect of the $1.0 \mathrm{~mm}$ interceptor integrated with three stern flaps.

\section{THE 3OM PATROL BOAT HSVA MODEL}

The second planning boat is $29.5 \mathrm{~m}$ in length and $6.628 \mathrm{~m}$ in breadth with draft of $1.7 \mathrm{~m}$. The displacement is 145 tons. The design speed is 32 knots. The $1 / 10$ bare hull wooden model was manufactured by HSVA (The Hamberg Ship Model Basin, Germany). Fig. 13 shows the body plan of the patrol boat. The resistance tests were done at the HSVA towing tank. $[10,11]$. The tests were conducted following the standard procedure at of HSVA towing tank.

The optimum height of the interceptor was determined from the comparison of resistance test results at the trial speed 30 knots of the trial condition only. The evaluated heights were $0 \mathrm{~mm}, 2 \mathrm{~mm}, 3 \mathrm{~mm}$ and $4 \mathrm{~mm}$. Two trim wedges of $4 \mathrm{~mm}$ height and $6 \mathrm{~mm}$ height with $35 \mathrm{~mm}$ length were also included. The test results are shown in Table.1. The 3 $\mathrm{mm}$ interceptor was selected as the height of the integrated interceptor with stern flap.

The evaluated angles of the stern flap were 0,4 and 8 degrees. The tested results are shown in Fig.14 and Fig. 15. At the design speed, the effective power of full scale for all test conditions are shown in table 2 . The test results show that the integrated $3 \mathrm{~mm}$ interceptor and 8 degrees stern flap delivers superior resistance performance.

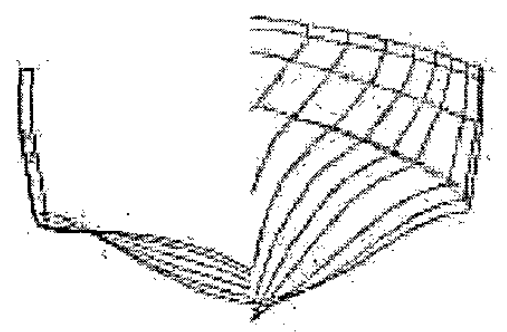

Fig. 13. Geometry of 145 tons patrol boat tested at HSVA
Table 1: HSVA Test results of trim mechanisms

\begin{tabular}{|c|c|c|}
\hline Tested Condition & Trim Mechanism & $10^{\star}$ Rtm/Disp. \\
\hline Trial $(\mathrm{d}=1.565 \mathrm{~m})$ & Bare Hull & 1.362 \\
\hline Trial $(\mathrm{d}=1.565 \mathrm{~m})$ & $2 \mathrm{~mm}$ Interceptor & 1.311 \\
\hline Trial $(\mathrm{d}=1.565 \mathrm{~m})$ & $3 \mathrm{~mm}$ Interceptor & 1.297 \\
\hline Trial $(\mathrm{d}=1.565 \mathrm{~m})$ & $4 \mathrm{~mm}$ Interceptor & 1.298 \\
\hline Trial $(\mathrm{d}=1.565 \mathrm{~m})$ & $4 \times 35 \mathrm{~mm}$ Wedge & 1.305 \\
\hline Trial $(\mathrm{d}=1.565 \mathrm{~m})$ & $6 \times 35 \mathrm{~mm}$ Wedge & 1.298 \\
\hline Full $(\mathrm{d}=1.700 \mathrm{~m})$ & 4 deg. Stern Flap & 1.307 \\
\hline Full $(\mathrm{d}=1.700 \mathrm{~m})$ & $8 \mathrm{deg}$. Stern Flap & 1.304 \\
\hline
\end{tabular}

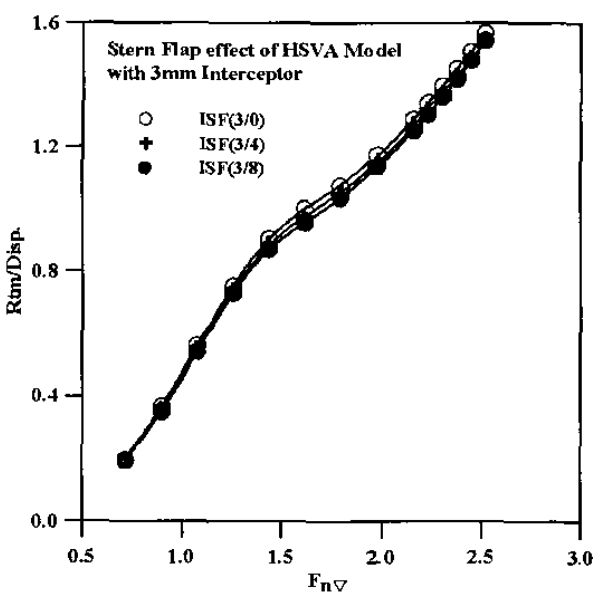

Fig.14. Resistance tested results of $3 \mathrm{~mm}$ interceptor with stern flaps.

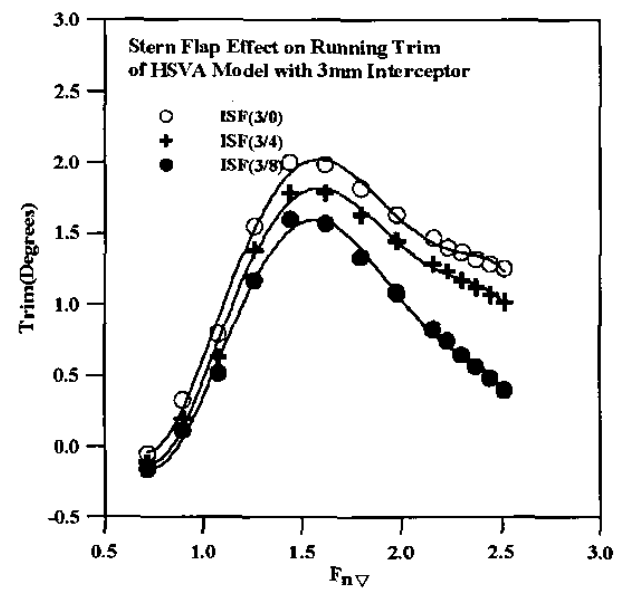

Fig.15. Running trims of $3 \mathrm{~mm}$ interceptor with stern flaps 
Table 2: Full Scale Effective Power at 32 Knots

\begin{tabular}{|c|c|c|c|}
\hline $\begin{array}{c}\text { Stern Flap } \\
\text { Angle }\end{array}$ & $\begin{array}{c}\text { Interceptor } \\
\text { Height(mm) }\end{array}$ & $\mathrm{RT}(\mathrm{kN})$ & $\mathrm{PE}(\mathrm{kW})$ \\
\hline 0 & 3 & 175 & 2887 \\
\hline 4 & 0 & 177 & 2911 \\
\hline 8 & 0 & 177 & 2919 \\
\hline 4 & 3 & 173 & 2855 \\
\hline 8 & 3 & 172 & 2824 \\
\hline
\end{tabular}

The comparisons of the effect of interceptor, stern flap and interated interceptor with stern flap on the resistance performance of HSVA model are shown in Fig.16. Fig.17 shows the results of running trim. Fig. 18 shows the results of heave. The integrated interceptor with stern flap configuration has the minimum resistance/displacement coefficient as shown in Fig. 16 and Table 3 . The running trim and heave of these three configurations at design speed are shown in Table 4. The integrated interceptor with stern flap configuration has the minimum value of running trim and heave at design speed also.

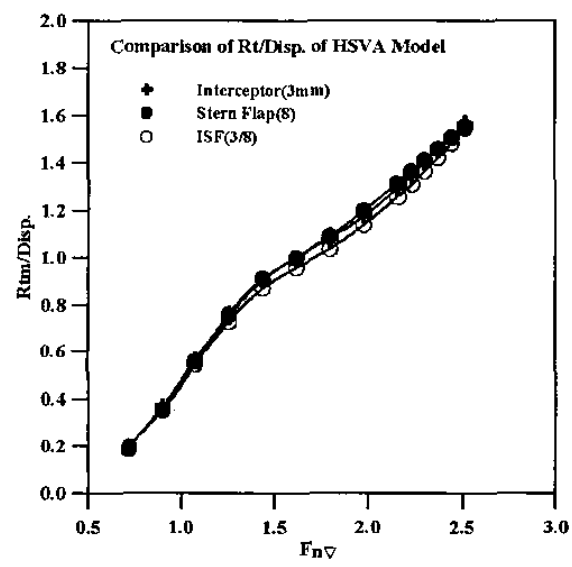

Fig.16. Comparison of resistance/displacement coefficient of HSVA model for different trim mechanisms

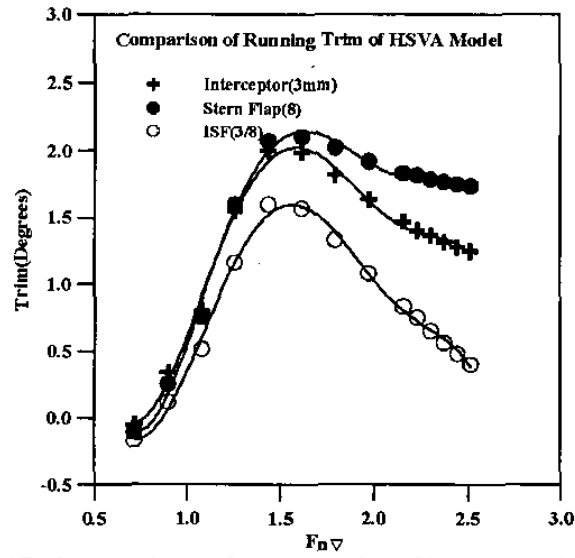

Fig.17. Comparison of running trim of HSVA model for different trim mechanisms

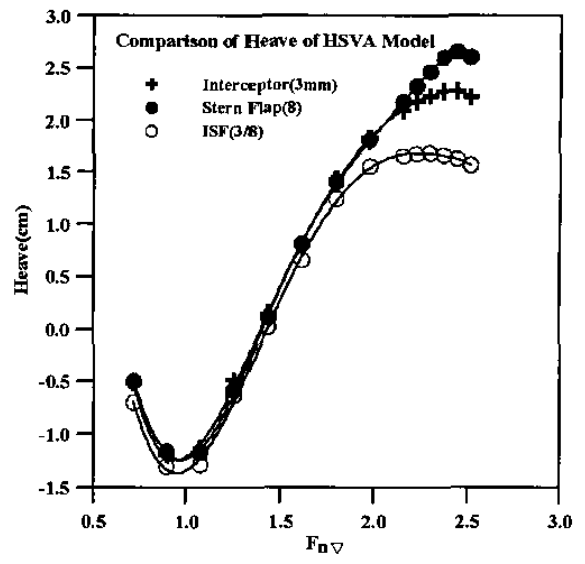

Fig.18. Comparison of heave of HSVA model for different trim mechanisms

Table 3. The Resistance/Displacement coefficient of HSVA Mode for different trim mechanisms

\begin{tabular}{|c|c|}
\hline Configurations & Resistance/Displacement \\
\hline 3mm Interceptor & 1.398 \\
\hline 8 Deg. Stern Flap & 1.410 \\
\hline ISF $(3 / 8)$ & 1.363 \\
\hline
\end{tabular}

Table 4. The Running Trim and Heave of HSVA Model for different trim mechanisms

\begin{tabular}{|c|c|c|}
\hline Configurations & $\begin{array}{c}\text { Running Trim } \\
\text { (Degree) }\end{array}$ & Heave(cm) \\
\hline 3mm Interceptor & 1.367 & 2.23 \\
\hline 8 Deg. Stern Flap & 1.783 & 2.46 \\
\hline ISF $(3 / 8)$ & 0.650 & 1.68 \\
\hline
\end{tabular}

\section{CONCLUSIONS}

The following conclusions can be drawn from the test results:

1. A well-designed trim mechanism, such as interceptor, stern flap and integrated interceptor and stern flap, can reduce the running trim and decrease the resistance of the planning craft.

2. The optimum trim mechanism of the NTU model is the integrated $0.5 \mathrm{~mm}$ interceptor with 4 degrees stern flap. The $21 \%$ drag reduction is obtained in this configuration at $\mathrm{Fn}=2.55$ and $12 \%$ drag reduction at design speed 40 knots.

3. The optimum trim mechanism of the HSVA model is also the integrated configuration made of a $3 \mathrm{~mm}$ interceptor and 8 degrees stern flap.

4. The maximum drag reduction by the trim mechanisms occurred at the range of the volume Froude number between 2.0 and 2.5 . 
5. The running trim of bare hull is about 4 degrees. The running trim of planning craft with trim mechanism could be reduced to about 1 degree to 2 degrees.

The optimum height of the interceptor and the angle of the stern flap were determined from the tests performed. The accuracy of the optimum values is limited due to the limited tests conducted. To develop a numerical method and an empirical method to predict the optimum value are encouraged.

\section{ACKNOWLEDGMENTS}

The authors would like to thank to the National Science Council of Taiwan, R.O.C. (NSC93-2516-S-002-001) and the Ministry of Economy, ROC for their financial support of this research.

\section{REFERENCES}

1. D. Savitsky, 'Planing Craft', Naval Engineers Journal, Feb., 1985.

2. G. Karafiath, and S.C. Fisher, 'The effect of Stern Wedges on Ship Powering Performance', Naval Engineers Journal, May, 1987.

3. CT. Wang, 'Wedge Effect on Planning Hulls', J. Hydronautics, Vol.14, No.4, 1980.

4. J.F. Tsai, J.L. Hwang, S.W. Chau, and S.K. Chou, 'Study of Hydrofoil Assistance Arrangement for Catamaran with Stern Flap and Interceptor', FAST 2001, Southampton, UK, Sep., 2001.

5. D.S. Cusanelli, and W.L. Cave, 'Effect of Stern Flaps on powering Performance of the FFG-7 Class', Marine Technology, Vol.30, No.1, Jan., 1993.

6. D.S. Cusanelli, and G. Karafiath, 'Advances in Stern Flap Design and application', FAST 2001, Southampton, UK, Sep., 2001.

7. J.F. Tsai, and J.K. Huang, 'Study on the Effect of Interceptor on high speed craft', Journal of the Society of Naval Architects and Marine Engineers, ROC, Vol.22, No. 2, 2003, pp.95-101.

8. J.F. Tsai, J. L. Hwang, S.W. Chau, and S.K. Chou," Study on the Compound Effects of Interceptor with Stern Flap for Two Fast Monohulls with Transom. Stern", FAST2003, Italy, 2003.

9. D.S. Cusanelli, and G. Karafiath, 'Integrated Wedge Flap for Enhanced Powering Performance', FAST'97, Sidney, Australia, July, 1997.

10. HSVA, 'Resistance Tests for a New 100 Tons Patrol Boat', HSVA Report WP 57/02, 2002.

11. HSVA, 'Resistance Tests for a New 100 Tons Patrol Boat', HSVA Report WP 65/02, 2002. 